\title{
Blunt vertebral artery injury in occipital condyle fractures
}

\author{
Joshua D. Burks, MD, Andrew K. Conner, MD, Robert G. Briggs, BS, Phillip A. Bonney, MD, \\ Adam D. Smitherman, MD, Cordell M. Baker, BS, Chad A. Glenn, MD, Cameron A. Ghafil, MD, \\ Dillon P. Pryor, BS, Kyle P. O'Connor, BS, and Bradley N. Bohnstedt, MD
}

Department of Neurosurgery, University of Oklahoma College of Medicine, Oklahoma City, Oklahoma

\begin{abstract}
OBJECTIVE A shifting emphasis on efficient utilization of hospital resources has been seen in recent years. However, reduced screening for blunt vertebral artery injury (BVAl) may result in missed diagnoses if risk factors are not fully understood. The authors examined the records of blunt trauma patients with fractures near the craniocervical junction who underwent CTA at a single institution to better understand the risk of BVAl imposed by occipital condyle fractures (OCFs).

METHODS The authors began with a query of their prospectively collected trauma registry to identify patients who had been screened for BVAl using ICD-9-CM diagnostic codes. Grade and segment were recorded in instances of BVAI. Locations of fractures were classified into 3 groups: 1) OCFs, 2) C1 (atlas) fractures, and 3) fractures of the C2-6 vertebrae. Univariate and multivariate analyses were performed to identify any fracture types associated with BVAI.
\end{abstract}

RESULTS During a 6-year period, 719 patients underwent head and neck CTA following blunt trauma. Of these patients, $147(20 \%)$ had OCF. BVAl occurred in 2 of 43 patients with type I OCF, 1 of 42 with type II OCF, and in 9 of 62 with type III OCF ( $p=0.12)$. Type III OCF was an independent risk factor for BVAl in multivariate modeling (OR $2.29[95 \% \mathrm{Cl}$ 1.04-5.04]), as were fractures of $\mathrm{C} 1-6$ (OR 5.51 [95\% $\mathrm{Cl} 2.57-11.83])$. Injury to the $\mathrm{V}_{4}$ segment was associated with type III OCF $(p<0.01)$.

CONCLUSIONS In this study, the authors found an association between type III OCF and BVAI. While further study may be necessary to elucidate the mechanism of injury in these cases, this association suggests that thorough cerebrovascular evaluation is warranted in patients with type III OCF.

https://thejns.org/doi/abs/10.3171/2018.3.SPINE161177

KEYWORDS blunt trauma; vertebral artery; cerebrovascular; injury; occipital condyle; cervical spine

$\mathrm{B}$ LUNT vertebral artery injuries (BVAIs) are rare in trauma patients but are potentially devastating when untreated. Documented injury rates suggest that BVAI occurs in less than $1 \%$ of all blunt trauma admissions. ${ }^{24,29}$ However, undiagnosed BVAI carries a poor prognosis; ${ }^{5}$ even with treatment, patients face high mortality rates ${ }^{5}$ and often have profound deficits. ${ }^{16,25}$ Our institution has routinely performed CTA of the head and neck in all patients with cervical spine and basilar skull fractures, respectively, as outlined by the modified Denver Screening Criteria for blunt cerebrovascular injury $(\mathrm{BCVI}){ }^{18}$

However, given the relatively low incidence of these injuries, modifications to screening criteria have been suggested to eliminate unnecessary imaging. ${ }^{4,6,9,18,27}$ To reduce unnecessary imaging, emphasis is placed on understand- ing the risk factors associated with BVAI ${ }^{26,31}$ There is currently a paucity of literature describing the relationship of occipital condyle fracture (OCF) and BVAI. At our institution, experience has led us to suspect such an association.

Considering the relationship between OCFs and BVAI may serve to optimize emergency management decisions. To this end, we examined the records of blunt trauma patients with fractures near the craniocervical junction who underwent CTA at our institution.

\section{Methods}

We identified all patients who underwent CTA for suspected BCVI at a single, Level I trauma center during a 6-year period (July 2009 to July 2015). Approval for this study was obtained from the institutional review board. 


\section{Collected Data}

We began with a query of the prospectively collected data in the trauma registry at our hospital to identify patients who had been screened for BVAI using ICD-9-CM diagnostic codes (801.00-801.99, 805.00-805.08, 805.10$805.18,806.00-806.09,806.10-806.19)$. We reviewed all relevant medical records. Prospectively collected data included sex, age, mechanism of injury, fracture grading, and hospital course. To be included, patients had to have a history and injury consistent with blunt trauma. Patients were excluded if their injury resulted from penetrating trauma such as a knife or missile wound.

All patients meeting the modified Denver Screening Criteria $^{18}$ underwent screening with CTA. All diagnoses were made by an attending neuroradiologist, with the primary outcome being BVAI. All BVAIs were graded according to the scale proposed by Biffl et al., ${ }^{7}$ wherein a grade I injury is characterized by intimal irregularity or dissection/hematoma with $<25 \%$ luminal stenosis, grade II injury is vessel dissection or thrombus with $\geq 25 \%$ luminal stenosis, grade III injury indicates the presence of a pseudoaneurysm, grade IV is vessel occlusion, and grade $\mathrm{V}$ is complete vessel transection. An instance of BVAI was included in our final analysis only if it occurred above the level of $V_{2}$. Any vertebral artery injury below $V_{2}$ was felt unlikely to be directly related to OCF and thus was not included in OCF comparisons.

OCFs were recorded as type I, II, or III according to the Anderson and Montesano classification. ${ }^{3}$ An illustration of the OCF variants based on this classification scheme is shown in Fig. 1. Fractures of the cervical spine were recorded for the purpose of statistical regression, given the known association between fractures of cervical vertebrae and BVAI. ${ }^{13}$ Any cervical spine fractures, excluding spinous process fractures, were also noted. Fractures of the C7 vertebra were not included, as the vertebral artery does not pass through $\mathrm{C} 7$ in $95 \%$ of patients. ${ }^{17}$

\section{Statistical Analysis}

Categorical variables are reported as frequencies and percentages, and continuous variables are reported as means with standard deviation. Univariate analysis was performed to identify associations between BVAI and clinical and radiographic risk factors. Comparisons were made using the chi-square test (alternatively, the Fisher exact test when more than $80 \%$ of the values were less than 5) for categorical variables and the unpaired t-test for continuous variables.

Multivariate analysis was performed with logistic regression and initially included all variables that had $\mathrm{p}$ values of $<0.20$ on univariate analysis. A variable was excluded from the model if its removal resulted in no significant difference in interpretation of other variables. Calibration was checked using the Hosmer-Lemeshow goodness-of-fit test. The final multivariate analysis results are presented as odds ratios with $95 \%$ confidence intervals.

A $p$ value $\leq 0.05$ was considered statistically significant. Data analysis was conducted using IBM SPSS (version 22, IBM Corp.).
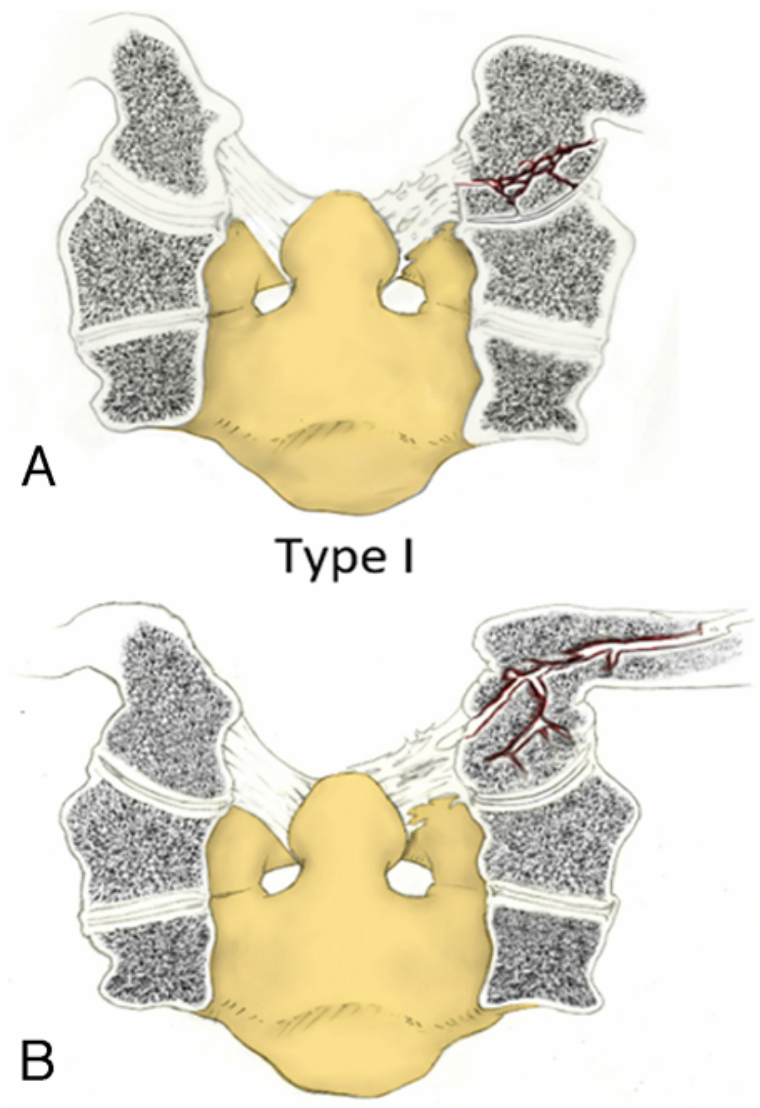

Type II

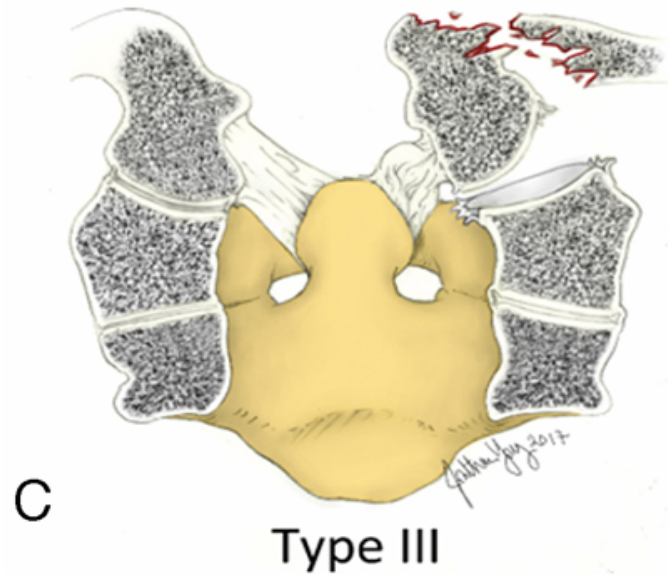

FIG. 1. Illustration of the 3 types of OCFs based on the Anderson and Montesano classification scheme. A: A type I comminuted fracture of the occipital condyle. B: A type II skull base fracture extending into the condyle. C: A type III avulsion fracture of the occipital condyle in the region of the alar ligament. Copyright Jonathan P. Young. Published with permission. Figure is available in color online only.

\section{Results \\ Patient Population}

During the 6-year period, 719 patients (mean age 41.8 years) underwent head and neck CTA after blunt trauma. Of these patients, 147 (20\%) had OCF. The most common causes of fracture were motor vehicle collisions (55\%) 
and motorcycle collisions (16\%). Most patients were male (69\%). Sixty-one (8\%) patients had BVAI diagnosed by CTA, with grades II and IV being the most common types of injury (39\% and $41 \%$, respectively). Fractures of C1-6 vertebrae were present in $465(65 \%)$ patients. The mean length of hospital stay for patients who suffered BVAI was $20 \pm 31$ days, and the mean length of stay for patients without BVAI was $14 \pm 16$ days $(\mathrm{p}=0.01)$. Complete patient demographics are given in Table 1.

\section{Variables Associated With BVAI}

BVAI occurring with OCF is given by vertebral artery segment and fracture type in Table 2. BVAI occurred in 2 of $43(5 \%)$ patients with type I OCF, 1 of $42(2 \%)$ with type II OCF, and in 9 of $62(14 \%)$ patients with type III OCF. Nine of $12(75 \%)$ injuries occurred with type III OCF, and 3 of $12(25 \%)$ injuries occurred with types I and II. Five of $9(56 \%)$ injuries occurred in the $\mathrm{V}_{4}$ segment ( $\mathrm{p}$ $<0.01$ ). Figure 2 illustrates the 4 segments of the vertebral artery as it traverses the cervical spine. A case example of a type III OCF fracture with $\mathrm{V}_{4}$ segment injury is shown in Fig. 3.

Univariate analysis of factors associated with BVAI is shown in Table 3. BVAI occurred in 9 of 62 (14\%) patients with OCF fractures $(\mathrm{p}=0.08)$. BVAI occurred in 52 of $465(11 \%)$ fractures of $\mathrm{C} 1-6$ vertebrae $(\mathrm{p}<0.01)$. Patients with BVAI had a mean age of $44.8 \pm 19.5(p=0.20)$. The mechanism of injury did not appear related to the occurrence of BVAI $(p=0.96)$.

The final variables included in the multivariate model were type III OCFs and fractures of C1-6 vertebrae. Type III OCF was an independent risk factor for BVAI (OR 2.29 [95\% CI 1.04-5.04], $\mathrm{p}=0.04$ ). Fractures of C1-6 were also an independent risk factor for BVAI (OR 5.51 [95\% CI 2.57-11.83], $\mathrm{p}<0.01)$. This is shown in Table 4.

\section{Discussion}

Screening for BVAI remains a challenge in the emergency management of trauma patients. Due to the poor prognosis of untreated BVAI, early diagnosis is critical. The cost and contrast burden that CTA places on patients requires careful consideration of fracture patterns that put patients at risk for BVAI. We reviewed the records of 719 patients from a prospectively collected trauma database, which allowed for reliable identification of all patients who underwent CTA of the neck after blunt traumatic injury to identify clinical and radiographic risk factors for cerebrovascular injury. Specifically, we examined the relationship between BVAI and fractures of the occipital condyle. Our multivariate model demonstrates an increased risk for BVAI in patients with type III OCFs, while accounting for the increased risk imposed by other fractures of the cervical spine. Type III OCF may serve to inform the nature of the trauma and the concurrent risk of BVAI, and in some cases, may also suggest a direct mechanism of injury.

\section{Occipital Condyle Fracture}

Our analysis suggests that the majority of BVAIs associated with OCF tend to occur with high-grade injury, which in our cohort occurred most commonly in high-ve-
TABLE 1. Patient characteristics

\begin{tabular}{|c|c|}
\hline Characteristic & Value \\
\hline No. of pts & 719 \\
\hline Male & $497(69)$ \\
\hline Female & $222(31)$ \\
\hline \multicolumn{2}{|l|}{ Age, yrs } \\
\hline Mean & $41.8 \pm 18.7$ \\
\hline Range & $3-91$ \\
\hline \multicolumn{2}{|l|}{ Fracture type } \\
\hline OCF & $147(20)$ \\
\hline $\mathrm{C} 1-6$ & $465(65)$ \\
\hline \multicolumn{2}{|l|}{ Mechanism of injury } \\
\hline MVC & $395(55)$ \\
\hline MVCP/assault & $64(9)$ \\
\hline MCC/ATV & $118(16)$ \\
\hline Other & $30(4)$ \\
\hline Fall & $112(16)$ \\
\hline No. of pts w/ BVAI & $61(8)$ \\
\hline \multicolumn{2}{|l|}{ Biffl grade of BVAl } \\
\hline I & $8(13)$ \\
\hline$\|$ & $24(39)$ \\
\hline III & $4(7)$ \\
\hline IV & $25(41)$ \\
\hline V & $0(0)$ \\
\hline \multicolumn{2}{|c|}{ Mean no. of hospital days ${ }^{*}$} \\
\hline w/ BVAI & $20 \pm 31$ \\
\hline w/o BVAl & $14 \pm 16$ \\
\hline
\end{tabular}

ATV = all-terrain vehicle; $\mathrm{MCC}=$ motorcycle collision; $\mathrm{MVC}=$ motor vehicle collision; $\mathrm{MVCP}=$ motor vehicle collision with pedestrian; pts = patients. Values are presented as the number of patients (\%) unless stated otherwise. Mean values are presented as the mean \pm SD.

${ }^{*} p=0.01$.

locity injuries. Past studies of OCF have cited incidences of $4.4 \%$ to $16.4 \%$ in cases of blunt trauma. ${ }^{8,21}$ One previous study by Reddy and colleagues linked craniocervical junction trauma with reduced flow velocities at $V_{3}$ and highlighted subtle changes in flow dynamics within this region of the vertebral artery ${ }^{28}$ Given the anatomical position of the occipital condyle anterior to the course of the vertebral artery as it enters the skull, ${ }^{1}$ it follows that increased translational force to the condyle increases the risk of vertebral artery injury as indicated by our data. However, it seems unlikely that an OCF in isolation is likely to cause direct trauma to the vertebral artery without significant fracture or dislocation.

TABLE 2. Vertebral artery segment injured by fracture type

\begin{tabular}{|c|c|c|c|c|}
\hline \multirow[b]{2}{*}{ OCF Type } & \multicolumn{3}{|c|}{ Vertebral Segment* } & \multirow[b]{2}{*}{$p$ Value $†$} \\
\hline & $\mathrm{V}_{2}$ & $V_{3}$ & $\mathrm{~V}_{4}$ & \\
\hline 1 & 1 & 1 & 0 & \\
\hline II & 0 & 1 & 0 & \\
\hline III & 3 & 1 & 5 & $<0.01$ \\
\hline
\end{tabular}

*Values represent the number of vertebral segments.

$\dagger$ Fisher exact test. 


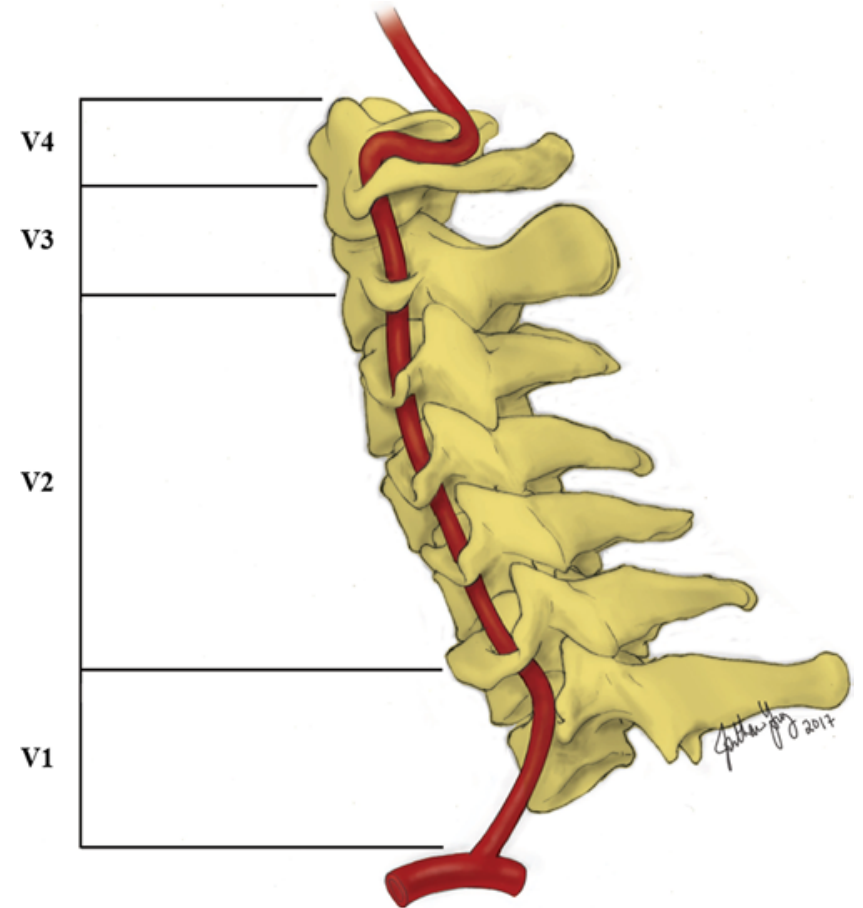

FIG. 2. Illustration of the segments of the vertebral artery. The $V_{1}$ segment extends from its origin to the $\mathrm{C} 6$ transverse foramen. $V_{2}$ extends from the transverse foramen of $\mathrm{C} 6$ to the transverse foramen of $\mathrm{C} 2 . \mathrm{V}_{3}$ extends from $\mathrm{C} 2$ to the dura. $\mathrm{V}_{4}$ extends from the dura to the confluence of the vertebral and basilar arteries. Copyright Jonathan P. Young. Published with permission. Figure is available in color online only.

\section{Screening Considerations}

While these data suggest that high-grade OCFs may warrant further evaluation for BVAI, available imaging modalities have inherent limitations. CTA has gained wide acceptance in trauma settings given its speed and excellent diagnostic accuracy. Conventional angiography remains the gold standard for diagnosis. ${ }^{11}$ However, patient selection for conventional angiography is dependent on the clinical scenario and is usually reserved for patients likely to require intravascular intervention. CTA has been
TABLE 3. Univariate analysis of factors associated with BVAI

\begin{tabular}{lcc}
\hline \multicolumn{1}{c}{ Characteristic } & No. of Pts w/ BVAl & p Value \\
\hline Sex & & 0.41 \\
Male & $45 / 497(9)$ & \\
Female & $16 / 222(7)$ & \\
\hline Mean age, yrs & $44.8 \pm 19.5$ & 0.20 \\
\hline Type III OCF & $9 / 62(14)$ & 0.08 \\
\hline Fractures of C1-6 vertebrae & $52 / 465(11)$ & $<0.01$ \\
\hline Mechanism of injury & & 0.96 \\
MVC & $35 / 395(9)$ & \\
MVCP/assault & $4 / 64(6)$ & \\
MCC/ATV & $10 / 118(8)$ & \\
Other & $2 / 30(7)$ & \\
Fall & $10 / 112(9)$ & \\
\hline
\end{tabular}

Values are presented as the number of patients (\%) unless stated otherwise. Mean values are presented as the mean $\pm \mathrm{SD}$.

validated with high specificity and sensitivity in patients meeting the Denver Screening Criteria. ${ }^{7}$ MRA has been described in screening for vertebral artery injuries, but it appears to be less sensitive than conventional angiography (sensitivity $=0.2)^{20}$ and is limited by resolution. ${ }^{7}$ Other authors have proposed the addition of flow-based imaging, relying on Doppler mechanics to increase the sensitivity of screening.?

The most definitive screening guidelines to date ${ }^{18}$ were adapted from the Denver Screening Criteria. ${ }^{7}$ Among the recommended criteria for CTA following blunt trauma are cervical or basilar skull fractures, infarct or cervical hematoma, and focal neurological deficits not explained by head CT imaging.? Others have additionally noted a strong association between combined $\mathrm{C} 1-2$ fractures and BVAI; ${ }^{7}$ however, we did not find an association between fractures of the atlas independently with BVAI. Previously, authors showed that hyperextension and subluxation injuries increase the risk of BVAI?

Typical treatment paradigms rely on the degree of injury and take into account the cervical injury and patient characteristics. For example, in most cases the presence of
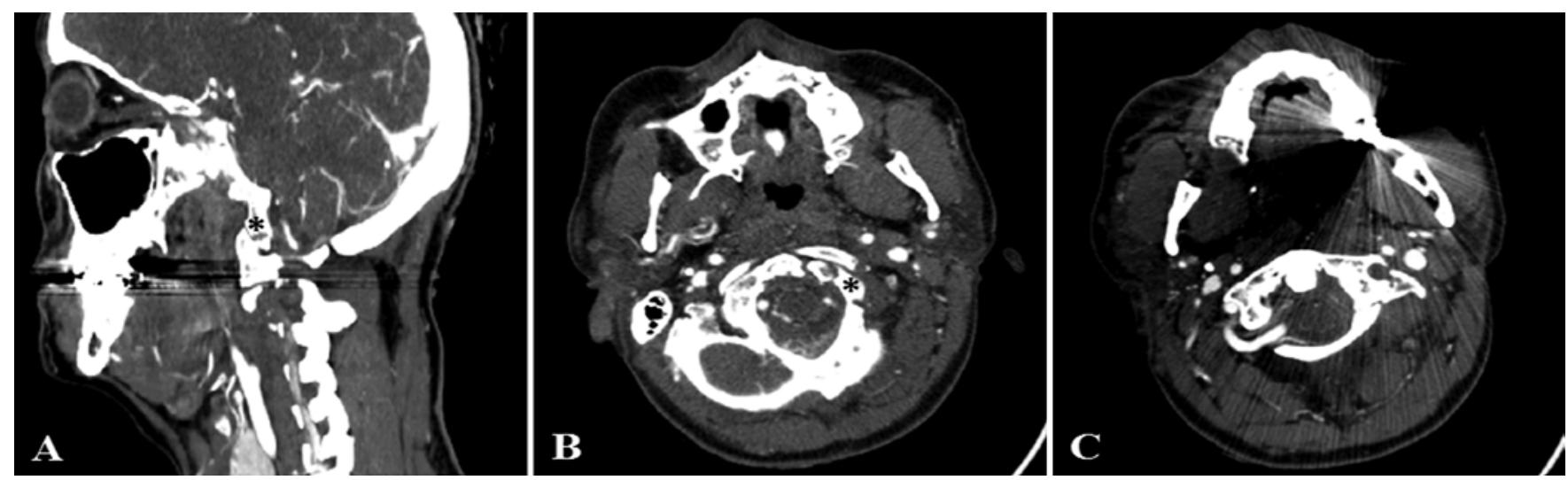

FIG. 3. Sagittal (A) and axial (B and C) CT angiograms obtained in a representative case of a type III OCF $\left(^{*}\right)$ with a grade IV BVAl. The vertebral artery occlusion extends from $\mathrm{C} 3$ to the occiput, encompassing the $\mathrm{V}_{2}$ and $\mathrm{V}_{3}$ segments of the artery. This was the case of a 40 -year-old woman in a motor vehicle collision. 
TABLE 4. Multivariate model of risk for BVAl in patients with fracture

\begin{tabular}{lcc}
\hline Fracture Type & OR $(95 \% \mathrm{Cl})$ & p Value \\
\hline Type III OCF & $2.29(1.04-5.04)$ & 0.04 \\
C1-6 & $5.51(2.57-11.83)$ & $<0.01$ \\
\hline
\end{tabular}

Homer-Lemeshow goodness-of-fit test $p=0.02$.

vertebral artery injury with juxtaposed cervical fracture is reevaluated with imaging after reduction of the fracture before additional treatment measures are considered. Adjuvant treatment usually involves anticoagulation therapy, ${ }^{12,15,23,30}$ and sometimes stenting with or without coiling, especially in cases of pseudoaneurysm. ${ }^{2,10}$ At our institution, we administer anticoagulant or antiplatelet medication in the early postoperative period (12-24 hours). While no standard of care has been established, the CADISS (Cervical Artery Dissection in Stroke Study) trial showed the benefit of medical therapy for cervical artery dissection within 7 days. ${ }^{22}$ Given the importance of stroke prevention, ${ }^{14}$ emphasis of any treatment plan relies on early detection of arterial injury, especially before operating, to protect the contralateral artery during surgery and to inform cautious manipulation of fractured bony structures ipsilateral to the lesion.

\section{Limitations}

Some authors have argued that reliance on clinical and radiological risk factors without angiographic studies is not adequately sensitive screening.14,19 Indeed, any attempts to reduce CTA utilization could increase the risk of BVAI going undetected until a complete understanding of the associated risks is achieved, and estimating the true cost reduction of alterations to current screening guidelines could prove difficult to achieve. Some authors have estimated the costs associated with CTA studies in $\mathrm{BCVI},{ }^{32}$ but costs associated with CTA at our own institution are beyond the scope of the present study. However, we would posit that type III OCF warrants a high clinical index of suspicion, even in the setting of continued efforts to reduce unnecessary resource utilization.

Although patients were uniformly screened with CTA based on criteria that encompassed all spine and occipital condyle fractures, this was not a randomized controlled trial. Given its retrospective nature and reliance on a trauma database, follow-up data were not available and outcomes are not presented. Additionally, the number of patients with isolated OCFs is relatively small due to the uncommon nature of the injury. Powering a larger study would likely require a longer study duration involving multiple institutions, which could fail to accurately capture incidence rates given variability in treatment and frequently changing screening techniques. The size of this study limits the strength of its conclusion but warrants further exploration of the relationship between OCF and BVAI.

\section{Conclusions}

Our data suggest that type III OCFs are correlated with BVAI. Specifically, the $\mathrm{V}_{4}$ segment is often involved when type III OCF is present. As screening for BVAI is continually refined, this relationship may justify further examination. High-grade OCF could warrant consideration of BVAI, as OCF informs a history of significant translational force required to place strain on the vertebral arteries.

\section{Acknowledgments}

We acknowledge Jonathan Young, MD, for his work in providing 2 medical illustrations for this article.

\section{References}

1. Akar A, Civelek E, Cansever T, Aydemir F, Altinors MN: The relationship of the vertebral artery with anatomical landmarks in the posterior craniovertebral junction of fresh human cadavers in the Turkish population. Turk Neurosurg 26:389-398, 2016

2. Almazedi B, Lyall H, Bhatnagar P, Kessel D, McPherson S, Patel JV, et al: Endovascular management of extra-cranial supra-aortic vascular injuries. Cardiovasc Intervent Radiol 37:55-68, 2014

3. Anderson PA, Montesano PX: Morphology and treatment of occipital condyle fractures. Spine (Phila Pa 1976) 13:731736, 1988

4. Beliaev AM, Barber PA, Marshall RJ, Civil I: Denver screening protocol for blunt cerebrovascular injury reduces the use of multi-detector computed tomography angiography. ANZ J Surg 84:429-432, 2014

5. Biffl WL, Moore EE, Elliott JP, Ray C, Offner PJ, Franciose $\mathrm{RJ}$, et al: The devastating potential of blunt vertebral arterial injuries. Ann Surg 231:672-681, 2000

6. Biffl WL, Moore EE, Offner PJ, Brega KE, Franciose RJ, Elliott JP, et al: Optimizing screening for blunt cerebrovascular injuries. Am J Surg 178:517-522, 1999

7. Biffl WL, Moore EE, Offner PJ, Burch JM: Blunt carotid and vertebral arterial injuries. World J Surg 25:1036-1043, 2001

8. Bloom AI, Neeman Z, Slasky BS, Floman Y, Milgrom M, Rivkind A, et al: Fracture of the occipital condyles and associated craniocervical ligament injury: incidence, CT imaging and implications. Clin Radiol 52:198-202, 1997

9. Burlew CC, Biffl WL, Moore EE, Barnett CC, Johnson JL, Bensard DD: Blunt cerebrovascular injuries: redefining screening criteria in the era of noninvasive diagnosis. J Trauma Acute Care Surg 72:330-337, 539, 2012

10. Burlew CC, Biffl WL, Moore EE, Pieracci FM, Beauchamp $\mathrm{KM}$, Stovall R, et al: Endovascular stenting is rarely necessary for the management of blunt cerebrovascular injuries. J Am Coll Surg 218:1012-1017, 2014

11. Chen CJ, Tseng YC, Lee TH, Hsu HL, See LC: Multisection CT angiography compared with catheter angiography in diagnosing vertebral artery dissection. AJNR Am J Neuroradiol 25:769-774, 2004

12. Cothren CC, Biffl WL, Moore EE, Kashuk JL, Johnson JL: Treatment for blunt cerebrovascular injuries: equivalence of anticoagulation and antiplatelet agents. Arch Surg 144:685690, 2009

13. Cothren CC, Moore EE, Biffl WL, Ciesla DJ, Ray CE Jr, Johnson JL, et al: Cervical spine fracture patterns predictive of blunt vertebral artery injury. J Trauma 55:811-813, 2003

14. Crawford JD, Allan KM, Patel KU, Hart KD, Schreiber MA, Azarbal AF, et al: The natural history of indeterminate blunt cerebrovascular injury. JAMA Surg 150:841-847, 2015

15. DiCocco JM, Fabian TC, Emmett KP, Magnotti LJ, Zarzaur BL, Bate BG, et al: Optimal outcomes for patients with blunt cerebrovascular injury (BCVI): tailoring treatment to the lesion. J Am Coll Surg 212:549-559, 2011

16. DiCocco JM, Fabian TC, Emmett KP, Magnotti LJ, Zarzaur 
BL, Khan N, et al: Functional outcomes following blunt cerebrovascular injury. J Trauma Acute Care Surg 74:955-960, 2013

17. Fassett DR, Dailey AT, Vaccaro AR: Vertebral artery injuries associated with cervical spine injuries: a review of the literature. J Spinal Disord Tech 21:252-258, 2008

18. Harrigan MR, Hadley MN, Dhall SS, Walters BC, Aarabi B, Gelb DE, et al: Management of vertebral artery injuries following non-penetrating cervical trauma. Neurosurgery 72 (Suppl 2):234-243, 2013

19. Jacobson LE, Ziemba-Davis M, Herrera AJ: The limitations of using risk factors to screen for blunt cerebrovascular injuries: the harder you look, the more you find. World J Emerg Surg 10:46, 2015

20. Lévy C, Laissy JP, Raveau V, Amarenco P, Servois V, Bousser MG, et al: Carotid and vertebral artery dissections: threedimensional time-of-flight MR angiography and MR imaging versus conventional angiography. Radiology 190:97-103, 1994

21. Link TM, Schuierer G, Hufendiek A, Horch C, Peters PE: Substantial head trauma: value of routine CT examination of the cervicocranium. Radiology 196:741-745, 1995

22. Markus HS, Hayter E, Levi C, Feldman A, Venables G, Norris J: Antiplatelet treatment compared with anticoagulation treatment for cervical artery dissection (CADISS): a randomised trial. Lancet Neurol 14:361-367, 2015

23. Miller PR, Fabian TC, Bee TK, Timmons S, Chamsuddin A, Finkle R, et al: Blunt cerebrovascular injuries: diagnosis and treatment. J Trauma 51:279-286, 2001

24. Miller PR, Fabian TC, Croce MA, Cagiannos C, Williams JS, Vang M, et al: Prospective screening for blunt cerebrovascular injuries: analysis of diagnostic modalities and outcomes. Ann Surg 236:386-395, 2002

25. Mitha AP, Kalb S, Ribas-Nijkerk JC, Solano J, McDougall $\mathrm{CG}$, Albuquerque FC, et al: Clinical outcome after vertebral artery injury following blunt cervical spine trauma. World Neurosurg 80:399-404, 2013

26. Nakajima H, Nemoto M, Torio T, Takeda R, Ooigawa $H$, Araki R, et al: Factors associated with blunt cerebrovascular injury in patients with cervical spine injury. Neurol Med Chir (Tokyo) 54:379-386, 2014

27. Payabvash S, McKinney AM, McKinney ZJ, Palmer CS, Truwit CL: Screening and detection of blunt vertebral artery injury in patients with upper cervical fractures: the role of cervical CT and CT angiography. Eur J Radiol 83:571-577, 2014
28. Reddy M, Reddy B, Schöggl A, Saringer W, Matula Ch: The complexity of trauma to the cranio-cervical junction: correlation of clinical presentation with Doppler flow velocities in the V3-segment of the vertebral arteries. Acta Neurochir (Wien) 144:575-580, 2002

29. Torina PJ, Flanders AE, Carrino JA, Burns AS, Friedman DP, Harrop JS, et al: Incidence of vertebral artery thrombosis in cervical spine trauma: correlation with severity of spinal cord injury. AJNR Am J Neuroradiol 26:2645-2651, 2005

30. Tso MK, Lee MM, Ball CG, Morrish WF, Mitha AP, Kirkpatrick AW, et al: Clinical utility of a screening protocol for blunt cerebrovascular injury using computed tomography angiography. J Neurosurg 126:1033-1041, 2017

31. Vilela MD, Kim LJ, Bellabarba C, Bransford RJ: Blunt cerebrovascular injuries in association with craniocervical distraction injuries: a retrospective review of consecutive cases. Spine J 15:499-505, 2015

32. Wang AC, Charters MA, Thawani JP, Than KD, Sullivan SE, Graziano GP: Evaluating the use and utility of noninvasive angiography in diagnosing traumatic blunt cerebrovascular injury. J Trauma Acute Care Surg 72:1601-1610, 2012

\section{Disclosures}

The authors report no conflict of interest concerning the materials or methods used in this study or the findings specified in this paper.

\section{Author Contributions}

Conception and design: Burks, Conner, Bohnstedt. Acquisition of data: Briggs, Bonney, Smitherman, Ghafil, Pryor, O'Connor. Analysis and interpretation of data: Burks, Conner, Glenn. Drafting the article: Burks, Smitherman, O'Connor. Critically revising the article: Briggs, Baker, Glenn. Reviewed submitted version of manuscript: Baker. Approved the final version of the manuscript on behalf of all authors: Briggs. Statistical analysis: Burks, Glenn, Pryor, Bohnstedt. Study supervision: Bohnstedt.

\section{Correspondence}

Bradley N. Bohnstedt: University of Oklahoma College of Medicine, Oklahoma City, OK. bradley-bohnstedt@ouhsc.edu. 